\title{
Bromosubstituted norbornadienes and their reversible photolytic transformation to quadricyclanes
}

\author{
Peter Hammersh $\varnothing \mathrm{j}^{1}$, Thomas Just Sørensen ${ }^{1}$, Anders $\varnothing$. Madsen ${ }^{1}$, Martin M. Nielsen ${ }^{2}$, and Klaus Bechgaard ${ }^{1}$. \\ ${ }^{1}$ Nano-Science Center \& Department of Chemistry, University of Copenhagen, København $\varnothing$, Denmark \\ ${ }^{2}$ Department of Physics, Technical University of Denmark, Fysikvej 307, 2800 Kgs. Lyngby \\ *Corresponding author's e-mail address: klbe@kiku.dk
}

Published online: September 5, 2014 (version 1)

Cite as: Hammershøj et al., ScienceOpen Research 2014 (DOI: 10.14293/S2199-1006.1.SOR-CHEM.AKS7SX.v1)

Reviewing status: Please note that this article is under continuous review. For the current reviewing status and the latest referee's comments please click here or scan the QR code at the end of this article.

Primary discipline: Organic \& Biomolecular chemistry

Keywords: Organic Synthesis, Norbornadiene Synthesis, Norbornadiene Scaffold, Bromosubstituted Quadricyclan, Bromosubstituted Norbornadiene

\begin{abstract}
Two new model systems for use within the rapidly developing ultrafast time resolved x-ray scattering techniques have been prepared. Their photoisomerisation from norbornadiene to quadricyclane was found to be a suitable reaction to follow. Simulations of scattering patterns (not included in this report) showed that if heavy atoms are included in these molecular structures, then the transformation can be followed by transient X-ray scattering techniques. Two new bromosubstituted norbornadienes were synthesised and characterised Absorption spectroscopy showed that the norbornadienes are converted quantitatively to quadricyclanes under ultraviolet irradiation. Nuclear magnetic resonance (NMR) studies showed that the process was fully reversible and that the norbornadienes could be completely recovered even without addition of catalysts. Furthermore, it was shown that the formation of quadricyclane from norbornadiene was unaffected by triplet sensitisers. The two new model systems synthesised thus are strong candidates for use in timeresolved X-ray scattering studies in both gas and condensed phases.
\end{abstract}

\section{INTRODUCTION}

Recent development of time-resolved X-ray scattering techniques have allowed for detection of the structure of several transient species employing a laser-pump and an X-ray scattering-probe [1-6]. Tracking nuclear motion in a solvent system enables the structural description of transients during the progression of a chemical reaction. The requirements for the systems that are to be investigated are strict. The lifetime of the transient species must be known, a large concentration of the species must be generated and the species must scatter $\mathrm{X}$-rays significantly different from the species present at equilibrium. In this article, potential candidates for the study of transients in a $2+2$ cycloaddition reaction with time-resolved
X-ray scattering studies in solution and the gas phase are presented.

The norbornadiene-quadricyclane system has been investigated as a potential system for solar energy storage [7-12]. The system has been a topic of intense interest [13-19], and a mechanism for the conversion from norbornadiene to quadricyclane has been proposed [7, 15, 20-29]. The mechanism is shown in Figure 1 and involves two transient species with different structures. If the mechanism is correct, the system will display a disappearance of $\mathbf{N}$, the grow-in and disappearance of ${ }^{3} \mathbf{D}_{\mathbf{N}}$ and ${ }^{3} \mathbf{D}_{\mathbf{Q}}$, and the finally grow-in of $\mathbf{Q}$ if investigated using a pump-probe technique capable of determining structural change.

Simulations employing structure minimisation and calculation of scattering patterns show that the structure of the different species can indeed be resolved by X-ray scattering if heavy atoms are substituted onto the system (assuming an overall quantum yield of $10 \%$ for the process). Furthermore, we speculated that if the heavy atoms were introduced in a conjugated system they would bring the systems absorption energy out of the ultraviolet (UV) region, minimising the chance of photoinduced carbon-bromine homolytic bond dissociation.

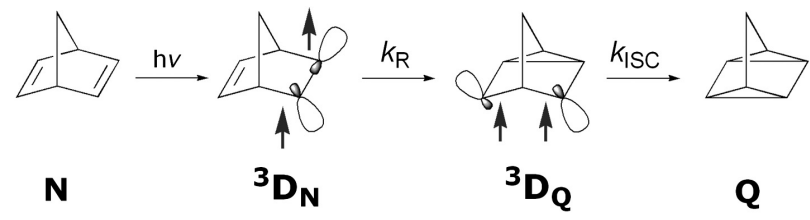

Figure 1. The mechanism of valence isomerisation from norbornadiene to quadricyclane. The different species are norbornadiene $(N)$, norbornadiene diradical $\left({ }^{3} D_{N}\right)$, quadricyclane diradical $\left({ }^{3} D_{Q}\right)$, quadricyclane $(Q)$. 
Two new norbornadienes were prepared with two and four bromine substituents, respectively. By absorption and NMR spectroscopy, both systems were shown to reversibly form the corresponding quadricyclanes.

\section{RESULTS AND DISCUSSION}

The synthetic route to 5,6-bis(4-bromophenyl)-7,7-dimethylnorbornadiene-2,3-dicarboxylic acid (8) and the corresponding bis(4-bromophenyl) ester (9) is shown in Scheme 1. The starting material 1 [30] was converted to the key intermediate: 2-hydroxy-4,4-dimethylcyclopent-2-enone (3), by an acyloin condensation [31-32]. The sodium/potassium alloy used in this step is highly flammable and limits the reaction scale to $10 \mathrm{~g}$. Two sequential reactions with 4-bromphenyllithium followed by dehydration with 4-toluenesulfonic acid give 2,3bis(4-bromphenyl)-5,5-dimethyl cyclopentadiene (7) in an overall yield of $26 \%$. Acetylenedicarboxylic and 7 underwent a Diels-Alder condensation in excellent yields to form the norbornadiene acid 8, which was made into the norbornadiene ester 9 via the acid chloride and 4-bromophenol. The multistep synthesis gave $\mathbf{8}$ and $\mathbf{9}$ in acceptable overall yields of $17 \%$ and $13 \%$, respectively.

The molecular structure of the sodium salt of $\mathbf{8}$ as crystallised from acetone was confirmed by single-crystal X-ray diffraction (CCDC 817053) and is shown in Figure 2. The structure clearly reveals the locked stilbene system that the bromine atoms are placed in. The aromatic rings may rotate, but the positions of the bromine atoms are fixed. In $\mathbf{9}$, the bromine

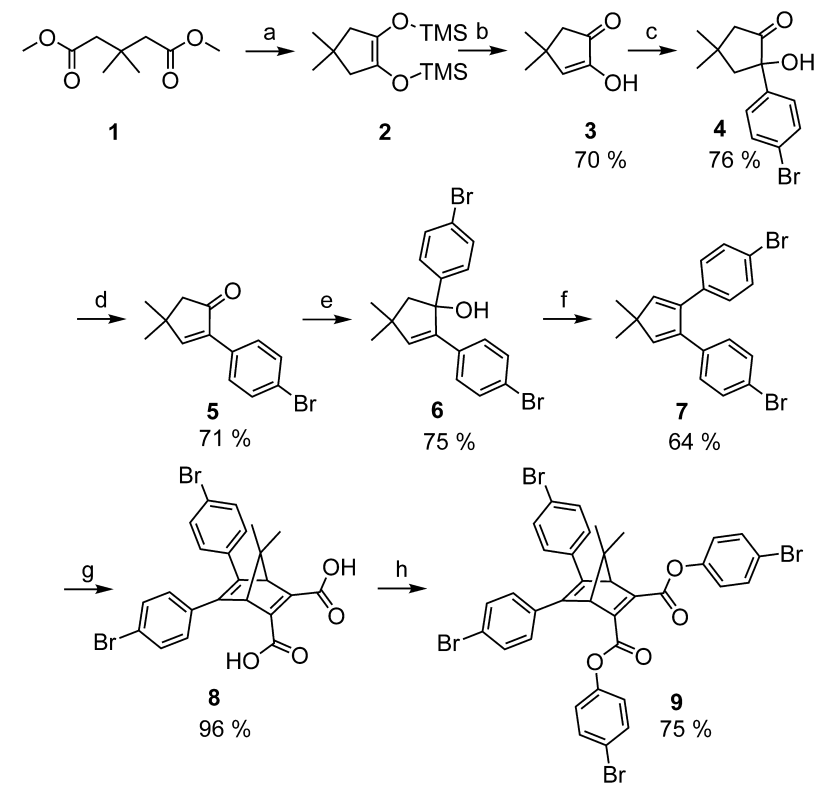

Scheme 1 (a). Na/K alloy, TMSCl, benzene; (b) $\mathrm{Br}_{2}$; (c) $n$-BuLi, $p$ dibromobenzene, $-78^{\circ} \mathrm{C}$; (d) $p$-TsOH, Toluene, reflux; (e) $n$-BuLi, p-dibromobenzene, $-78^{\circ} \mathrm{C}$; (f) $p$ - $\mathrm{TsOH}$, toluene, reflux; (g) Butynedioic acid, toluene, reflux; (h) 1. Oxalylchloride, DMF, $\mathrm{Et}_{3}$ N. 2. DMAP, $p$-bromophenol.

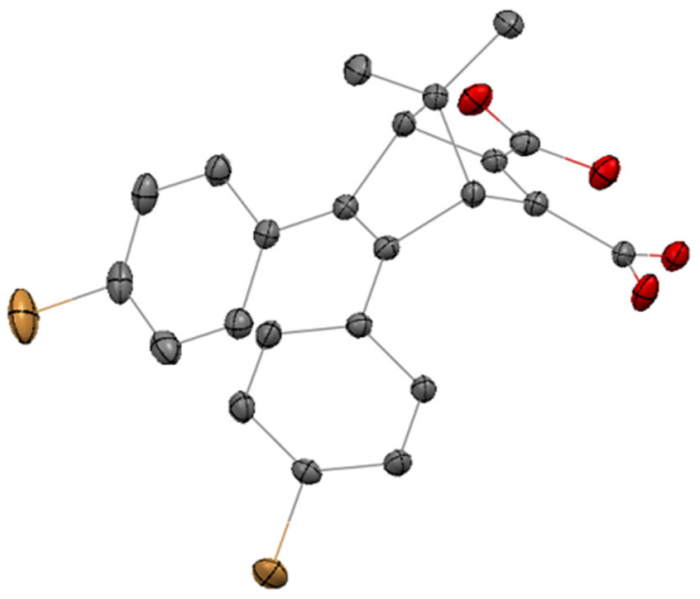

Figure 2. Single crystal structure of 5,6-bis(4-bromophenyl)-7,7dimethylnorbornadiene-2,3-dicarboxylic acid (8) as its sodium salt. Hydrogen atoms, sodium ions and solvent molecules are omitted for clarity. The structure is shown with $50 \%$ probability ellipsoids.

atoms in the ester groups have a higher degree of freedom and more conformers are possible. Even so, the structural changes when norbornadiene becomes quadricyclane will result in systematic changes in the interatomic distances, in particular for the bromine atoms in $\mathbf{8}$ and $\mathbf{9}$. The bromine atoms contribute very significantly to the X-ray scattering signature of the systems by introducing a strong modulation in the electron density distribution. Hence, these changes can be monitored using time-resolved X-ray scattering techniques. The bromine atoms account for more than $25 \%$ of the total electrons of the system.

If the norbornadienes $\mathbf{8}$ and $\mathbf{9}$ are to be studied using ultrafast X-ray scattering techniques, it must first be shown that the norbornadienes $\mathbf{8}$ and $\mathbf{9}$ can undergo photolytic isomerisation to the corresponding quadricyclanes $\mathbf{8 q}$ and $\mathbf{9 q}$ As triplet states are involved in the transformation [7-12], the bromine atoms might make the process slow or prevent it from happening. Two photolysis experiments are shown in Figure 3. It clearly shows a reaction happening. A NMR investigation of the photolysis product confirms that the quadricyclane is the only product formed. The photolysis was carried out for 8 and 9 using $290 \mathrm{~nm}$ and $350 \mathrm{~nm}$ light in several solvents (Benzene, $\mathrm{CHCl}_{3}, \mathrm{CH}_{3} \mathrm{CN}, \mathrm{CH}_{3} \mathrm{OH}$ ). Although, the absorption is strongest at $290 \mathrm{~nm}$, the produced quadricyclanes also absorb light at this wavelength. Hence, $350 \mathrm{~nm}$ light was used in the experiments shown here.

The effect of triplet sensitisers was tested using identical conditions as those used to generate the data in Figure 3. No effect of the sensitisers was found. The data are in all cases identical to those shown in Figure 3 when the sensitiser absorbance has been subtracted. The bromine atoms seem to act as internal triplet sensitisers and as such allow for an efficient conversion from norbornadiene to quadricyclane. 

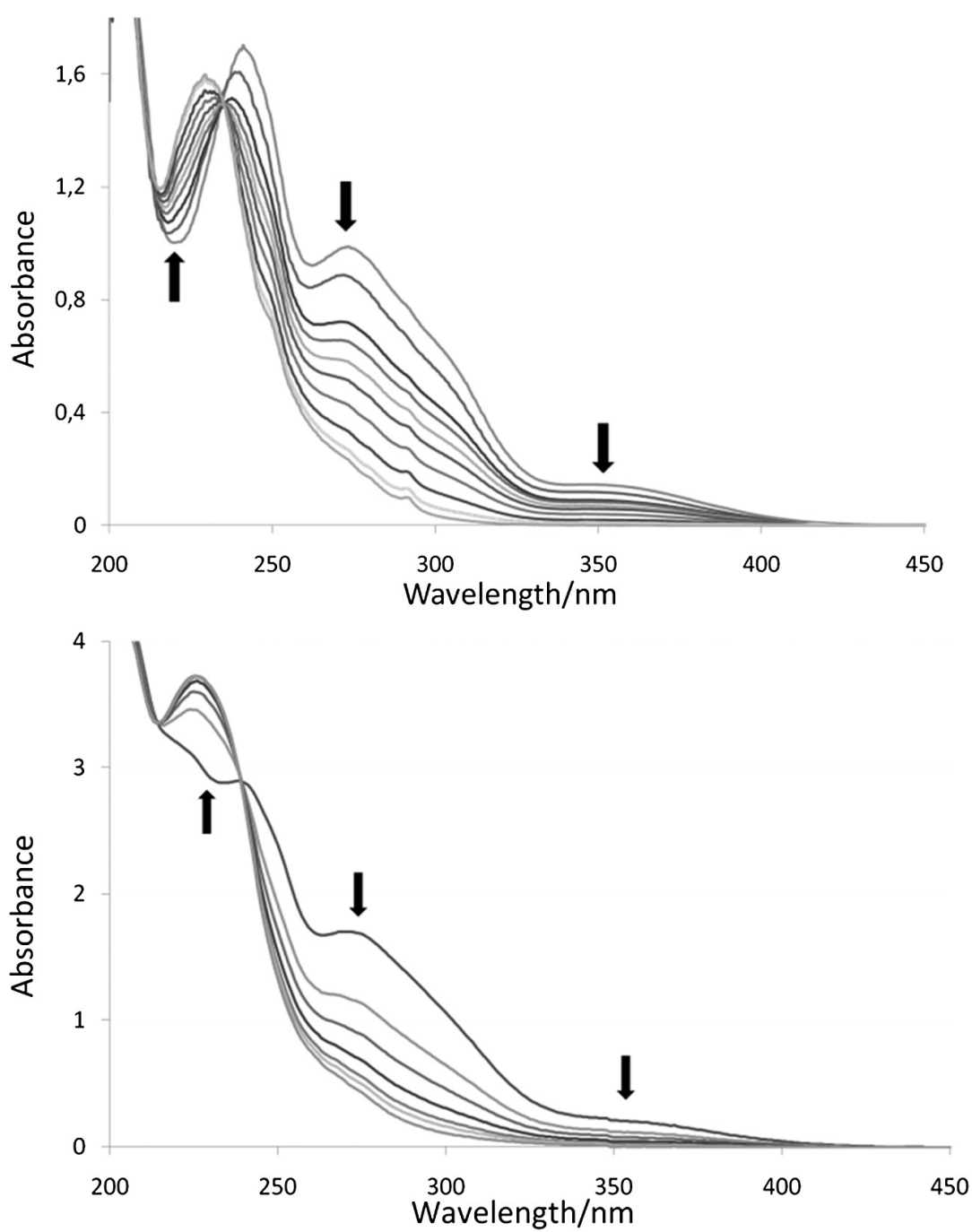

Figure 3. Photolysis of the norbornadiene acid 8 (top) and 9 (bottom) to the corresponding quadricyclane in methanol with $350 \mathrm{~nm}$ irradiation. The data points are at $2,4,6,8,10,14,20,30$, and 60 minutes.

The photolysis was also carried out in deuterated solvents in order to perform NMR experiments. Using NMR, it was determined that the photostationary state at $350 \mathrm{~nm}$ gave a ratio of $[\mathbf{Q}] /[\mathbf{N}]=92: 8$ in chloroform and 90:10 in benzene.

In most cases, the reverse process, from quadricyclane to norbornadiene, has to be catalysed [26, 33]. Furthermore, the quadricyclane formation is not fully reversible in the known systems [34]. In both $\mathbf{8 / 8 q}$ and $\mathbf{9 / 9 q}$, the photolysis is fully thermally reversible. Figure 4 shows a time-lapse NMR experiment in deutero-chloroform. It shows the thermal regeneration of norbornadiene over 12 hours at room temperature. The sample is kept in the dark.

Figure 5 shows the kinetic traces generated from the NMR experiments in deutero-chloroform and deutero-benzene. The $t_{1 / 2}=3$ hours and the half-life is the same for all investigated solvents and the same for both systems $\mathbf{8 / 8 q}$ and $\mathbf{9 / 9 q}$. After
24 hours, no traces of quadricyclane or other impurities remain. Thus, the system can be cycled repeatedly between norbornadiene and quadricyclane without loss of material.

\section{CONCLUSIONS}

Two new norbornadienes with bromine substituents have been synthesised and characterised. They are both capable of photolytic valence isomerisation to quadricyclane and can thermally be converted back to norbornadiene. The full recovery of the norbornadiene, combined with the unsensitised photoactivated isomerisation, make these systems good candidates for time-resolved X-ray studies using pump-probe techniques. The structural changes when going from norbornadiene over the relevant intermediates to quadricyclane are accompanied by the significant changes in electron density distribution due to the bromine atoms and can therefore be probed directly by X-ray scattering. 


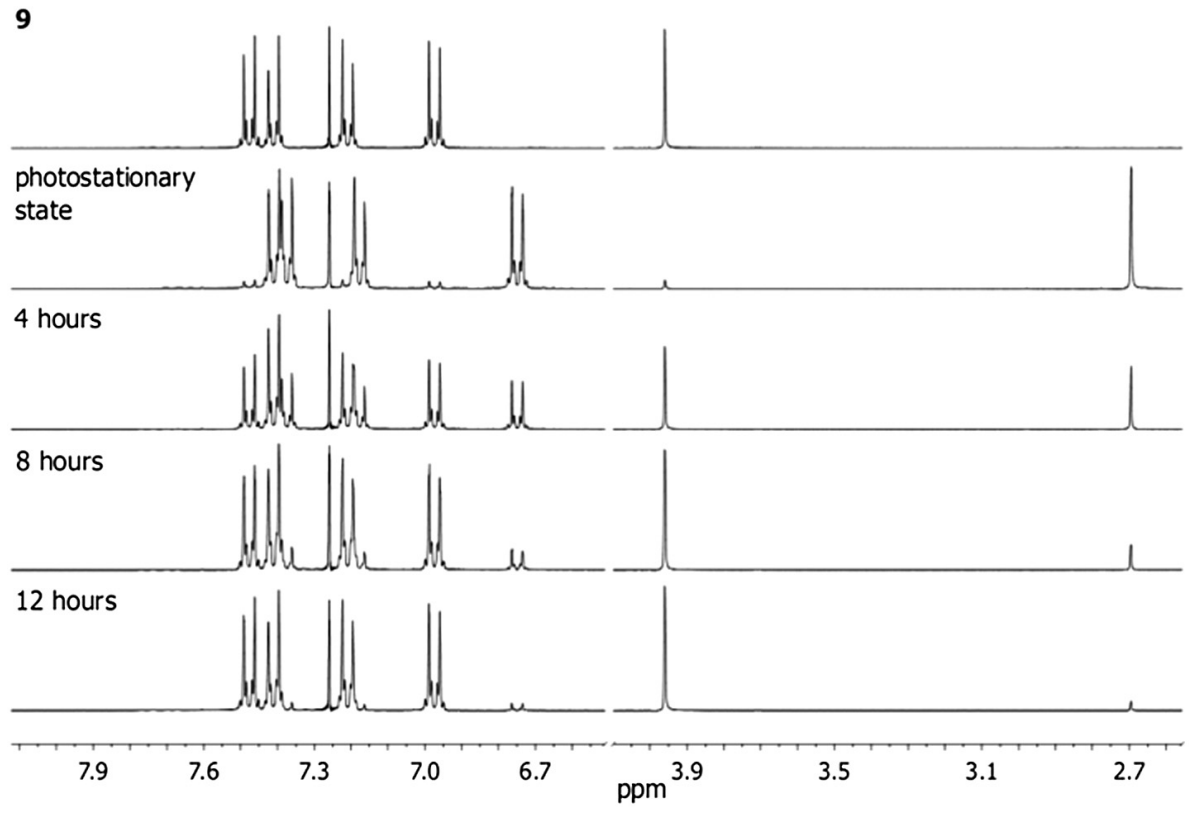

Figure 4. ${ }^{1} \mathrm{H}$ NMR spectra of quadricyclane to 9 dark at $\mathrm{RT}$ in $\mathrm{CDCl}_{3}$ after illumination at $350 \mathrm{~nm}$. The singlet at $3.9 \mathrm{ppm}$ is from 9 and the singlet at $2.7 \mathrm{ppm}$ is from the corresponding quadricyclane.

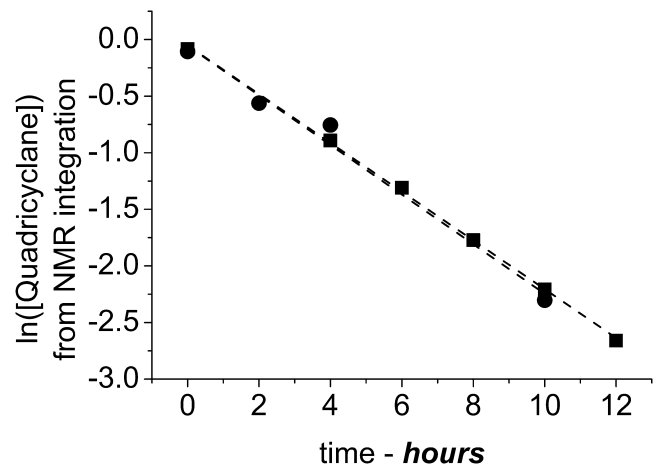

Figure 5. Kinetic traces of the formation of norbornadiene 9 in chloroform (squares) and benzene (circles) from time lapse ${ }^{1} \mathrm{H}$ NMR spectra. The liniear fit to the data points are shown as dashed lines.

\section{EXPERIMENTAL SECTION}

Unless otherwise stated, all starting materials were obtained from commercial suppliers and used as received. Solvents were of HPLC grade and were used as received. Ground-state absorption spectroscopy was routinely recorded with a Cary 100 Bio spectrophotometer as solutions in the stated solvents. ${ }^{1} \mathrm{H}$ NMR and ${ }^{13} \mathrm{C}$ NMR spectra were recorded on a 400 $\mathrm{MHz}$ (Varian) instrument (400 $\mathrm{MHz}$ for ${ }^{1} \mathrm{H}$ NMR and 100 $\mathrm{MHz}$ for ${ }^{13} \mathrm{C} \mathrm{NMR}$ ) or on a $500 \mathrm{MHz}$ (Varian) instrument (500 $\mathrm{MHz}$ for ${ }^{1} \mathrm{H}$ NMR and $125 \mathrm{MHz}$ for ${ }^{13} \mathrm{C}$ NMR). Proton chemical shifts are reported in ppm downfield from tetramethylsilane (TMS) and carbon chemical shifts in ppm downfield of TMS, using the resonance of the solvent as internal standard.
Melting points were measured on a Gallenkamp apparatus and are uncorrected. High resolution mass spectrometry (HRMS) were recorded on a Micromass Q-TOF apparatus using electrospray ionisation (ESI) technique. Matrix assisted laser desorption ionisation time of flight (MALDI-TOF) mass spectra were recorded on a VG TofSpec spectrometer. Electrospray ionisation (ESI) was recorded on a ThermoQuest Finnigan LCQ DECA instrument. Dry column vacuum chromatography was performed on Merck Kiselgel 60 (0.015-0.040 $\mathrm{mm}$ ) and gravity feed column chromatography was performed on Merck Kiselgel 60 (0.040-0.063 mm). Thin layer chromatography (TLC) was carried out using aluminium sheets pre-coated with silica gel 60F (Merck 5554).

4,4-Dimethyl-1,2-cyclopentadione/2-hydroxy-4,4-dimethylcyclopent-2-enone (3). A flame-dried 2-L tree-necked round-bottom flask equipped with a reflux condenser, addition funnel and a mechanical stirrer was maintained under an oxygen-free, nitrogen atmosphere. The flask is charged with freshly cut sodium (60 g) and freshly cut potassium (12 g), and the flask is heated with a heat gun, forming the low-melting alloy. Dry benzene $(1200 \mathrm{~mL})$ is added, and the stirrer is operated at high speed until the alloy is dispersed and then at a slower speed for the remaining reaction time. The dispersion was kept at $25^{\circ} \mathrm{C}$ and diester 1 (21.4 g, $0.11 \mathrm{~mol}$ ), and $\mathrm{Me}_{3} \mathrm{SiCl}$ $(87.6 \mathrm{~g}, 0.8 \mathrm{~mol})$ was dissolved in dry benzene $(100 \mathrm{~mL})$ and added carefully through the addition funnel. After 20 hours with rapid stirring, the mixture was filtered through a plug of celite under an argon atmosphere and concentrated in vacuo to give a colourless oil of compound 2. TLC $\left(50 \% \mathrm{CH}_{2} \mathrm{Cl}_{2} /\right.$ Hexane) $R_{f}=0.8$; Gas chromatography mass spectrometry (GCMS) (m/z (intensities)): 272 (100), 147 (44), 73 (85). The 
oil was dissolved in dry $\mathrm{CH}_{2} \mathrm{Cl}_{2}(500 \mathrm{~mL})$ at $-78^{\circ} \mathrm{C}$ under an $\mathrm{N}_{2}$ atmosphere, and $\mathrm{Br}_{2}(17.8 \mathrm{~g}, 1.1 \mathrm{~mol})$ was added dropwise over a 5-minute period, and the reaction was allowed to warm to $25^{\circ} \mathrm{C}$. The mixture was concentrated in vacuo. The product was purified by dry column vacuum chromatography (from heptane to EtOAc-heptane with $10 \%$ increments). Yield: $10.1 \mathrm{~g}, 72 \%$; TLC (50\% $\mathrm{CH}_{2} \mathrm{Cl}_{2} /$ Hexane) $R_{f}=0.8$; ${ }^{1} \mathrm{H}$ NMR $\left(\mathrm{CDCl}_{3}, 300 \mathrm{MHz}\right): \delta 6.41(\mathrm{~s}, 1 \mathrm{H}), 6.23(\mathrm{~s}, 1 \mathrm{H})$, 2.30 (s, 2H), 1.25 (s, 6H); GCMS (m/z (intensities)): 126 (35), 111 (100), 83 (45), 55 (45), 43 (50).

2-(4-Bromophenyl)-2-hydroxy-4,4-dimethylcyclopentanone (4). A flame-dried 50-mL round-bottom flask equipped with a rubber septum was added $p$-Dibromobenzene (3.54 g, 15 mmol) dissolved in a mixture of THF (30 mL) and diethyl ether $(30 \mathrm{ml}) . n$-Butyllithium $(2.5 \mathrm{M}$ in hexane, $6 \mathrm{ml}, 15$ mmol) was added dropwise using a syringe at $-78^{\circ} \mathrm{C}$ under a nitrogen atmosphere. After stirring under argon at $-78^{\circ} \mathrm{C}$ for an additional half an hour, 2-hydroxy ketone 3 (500 mg, $3.96 \mathrm{mmol}$ ) dissolved in dry diethyl ether $(15 \mathrm{~mL})$ was added dropwise using a syringe, then the mixture was allowed to reach room temperature over a period of 16 hours. The reaction mixture was quenched in ice water and extracted with ether $(2 \times$ $50 \mathrm{~mL})$. The extracts was washed with brine $(50 \mathrm{~mL})$, dried with $\mathrm{MgSO}_{4}$ and evaporated to dryness in vacuo. Purification by dry column vacuum chromatography (from heptane to EtOAc-heptane with $5 \%$ increments, starting by washing with heptane) yielded: $860 \mathrm{mg}, 76 \%$; m.p. $=94-95^{\circ} \mathrm{C}$; TLC $(50 \%$ EtOAc/Hexane) $R_{f}=0.9 ;{ }^{1} \mathrm{H}$ NMR $\left(\mathrm{CD}_{3} \mathrm{CN}, 400 \mathrm{MHz}\right): \delta 7.51$ (d, $2 \mathrm{H}, J=8.8 \mathrm{~Hz}$ ), 7.30 (d, $2 \mathrm{H}, J=8.8 \mathrm{~Hz}$ ), 3.89 (s, 1H), 2.40 (q, $2 \mathrm{H}, J=16.8 \mathrm{~Hz}), 2.17(\mathrm{~m}, 2 \mathrm{H}), 1.23(\mathrm{~s}, 3 \mathrm{H}), 1.16(\mathrm{~s}, 3 \mathrm{H})$; ${ }^{13} \mathrm{C}$ NMR $\left(\mathrm{CDCl}_{3}, 100 \mathrm{MHz}\right): \delta 217.2,143.5,131.4,127.9$, $120.9,81.2,53.5,52.8,33.1,29.6,28.9 ;$ GCMS (m/z (intensities)): 200 (97), 198 (100), 185 (52), 183 (55); Anal. Calcd. For $\mathrm{C}_{13} \mathrm{H}_{15} \mathrm{BrO}_{2}$ : C, 55.14; $\mathrm{H}, 5.35$; Found: C, 54.16; H, 5.35 . 2-(4-Bromophenyl)-4,4-dimethylcyclopent-2-enone (5). In a $100-\mathrm{mL}$ three-necked round-bottom flask equipped with a magnetic stirrer, a reflux condenser was added a solution of hydroxy-cyclopentanone 4 (3.0 g, $10.6 \mathrm{mmol})$ dissolved in toluene $(120 \mathrm{~mL})$ and $\mathrm{TsOH} \cdot \mathrm{H}_{2} \mathrm{O}(2.0 \mathrm{~g}, 10.8 \mathrm{mmol})$ was added. The mixture was heated to reflux for 40 minutes. The reaction mixture was allowed to cool to room temperature and then poured into $10 \% \mathrm{NaOH}$ solution $(100 \mathrm{~mL})$ and extracted with diethyl ether $(2 \times 50 \mathrm{~mL})$. The extracts were washed with brine $(100 \mathrm{~mL})$, dried with $\mathrm{MgSO}_{4}$ and evaporated to dryness in vacuo. Purification by dry column vacuum chromatography (from heptane to EtOAc-heptane with $10 \%$ increments) yielded: 2.0 g, $71 \%$; m.p. $=65-67^{\circ} \mathrm{C}$; TLC $(20 \%$ EtOAc/Hexane) $R_{f}=0.5 ;{ }^{1} \mathrm{H} \mathrm{NMR}\left(\mathrm{CDCl}_{3}, 500 \mathrm{MHz}\right): \delta 7.60(\mathrm{~d}$, $2 \mathrm{H}, J=8.5 \mathrm{~Hz}), 7.58(\mathrm{~s}, 1 \mathrm{H}), 7.59(\mathrm{~d}, 2 \mathrm{H}, J=8.5 \mathrm{~Hz}), 2.47(\mathrm{~s}$, $2 \mathrm{H}), 1.30(\mathrm{~s}, 6 \mathrm{H}) ;{ }^{13} \mathrm{C} \mathrm{NMR}\left(\mathrm{CDCl}_{3}, 100 \mathrm{MHz}\right) \delta 207.08$, $168.25,139.33,131.76,130.43,128.97,122.74,51.62,38.55$, 28.43; GCMS (m/z (intensities)): 266 (53), 264 (55), 251 (42), 249 (44), 157 (40), 142 (100); Anal. Calcd. For $\mathrm{C}_{13} \mathrm{H}_{13} \mathrm{BrO}$ : C, 58.89; H, 4.94; Found: $\mathrm{C}, 58.65$; H, 5.02.
1,2-Bis(4-bromophenyl)-4,4-dimethylcyclopent-2-en-1-ol (6). A flame-dried 50-mL round-bottom flask equipped with a rubber septum was added $p$-dibromobenzene (3.54 g, $15 \mathrm{mmol}$ ) dissolved in a mixture of dry THF (30 mL) and dry diethyl ether $(30 \mathrm{~mL})$. $n$-Butyllithium $(2.5 \mathrm{M}$ in hexanes, $5 \mathrm{~mL}, 1.3$ mmol,) was added dropwise using a syringe at $-78^{\circ} \mathrm{C}$ under a nitrogen atmosphere. After stirring under argon at $-78^{\circ} \mathrm{C}$ for an additional half hour, cyclopentenone 5 (1.00 g, $3.77 \mathrm{mmol})$ dissolved in dry diethyl ether $(15 \mathrm{~mL})$ was added dropwise using a syringe and then the mixture was allowed to reach room temperature over a period of 16 hours. The reaction mixture was quenched in a ice water $(200 \mathrm{~mL})$ and extracted with ether $(2 \times 100 \mathrm{~mL})$. The extracts were washed with brine, dried with $\mathrm{MgSO}_{4}$ and evaporated to dryness in vacuo. Purification by dry column vacuum chromatography (from heptane to EtOAc-heptane with 50\% increments, starting by washing with heptane) yielded: 1.2 g, 75\%; m.p. $=103-106^{\circ}$ C; TLC (20\% EtOAc/Hexane) $R_{f}=0.7 ;{ }^{1} \mathrm{H}$ NMR $\left(\mathrm{CD}_{3} \mathrm{CN}, 400\right.$ $\mathrm{MHz}$ ): $\delta^{1} \mathrm{H}$ NMR $\left(400 \mathrm{MHz}, \mathrm{CDCl}_{3}\right) \delta 7.31(\mathrm{~d}, 2 \mathrm{H}, J=8.8 \mathrm{~Hz})$, $7.21(\mathrm{~m}, 4 \mathrm{H}), 7.13(\mathrm{~d}, 2 \mathrm{H}, J=8.8 \mathrm{~Hz}), 6.22,(\mathrm{~s}, 1 \mathrm{H}), 2.16(\mathrm{~d}$, $2 \mathrm{H}, J=4.2 \mathrm{~Hz}), 1.22(\mathrm{~s}, 3 \mathrm{H}), 1.09(\mathrm{~s}, 3 \mathrm{H}) ;{ }^{13} \mathrm{C} \mathrm{NMR}\left(\mathrm{CDCl}_{3}\right.$, $101 \mathrm{MHz}) \delta 146.04,143.41,141.87,132.96,131.56,131.51$, 128.96, 127.37, 121.49, 120.71, 88.35, 77.58, 77.26, 76.94, 60.64, 42.90, 30.81, 29.11; GCMS (m/z(intensities)): 422 (45), 225 (54), 223 (58), 185 (98), 183 (100), 128 (64); Anal. Calcd. For $\mathrm{C}_{19} \mathrm{H}_{18} \mathrm{Br}_{2} \mathrm{O}$ : C, 50.06; H, 4.30; Found: C, 50.09; $\mathrm{H}, 4.38$.

2,3-bis(p-bromphenyl)-5,5-dimethyl cyclopentadiene (7). In a $100-\mathrm{mL}$ three-necked round-bottom flask equipped with a magnetic stirrer, a reflux condenser was added a solution of hydroxyl-cyclopentenone 6 (1.2 g, $2.4 \mathrm{mmol})$ dissolved in toluene $(50 \mathrm{~mL})$ and $\mathrm{TsOH} \cdot \mathrm{H}_{2} \mathrm{O}(480 \mathrm{mg}, 2.5 \mathrm{mmol})$ was added. The mixture was heated to reflux for 40 minutes. The mixture were poured into $10 \% \mathrm{NaOH}$ solution and extracted with diethyl ether $(3 \times 50 \mathrm{~mL})$. The extracts were washed with brine $(100 \mathrm{~mL})$, dried with $\mathrm{MgSO}_{4}$ and evaporated to dryness in vacuo. Purification by dry column vacuum chromatography (heptane) yielded: $740 \mathrm{mg}, 64 \%$; m.p. $=158-159^{\circ} \mathrm{C}$; TLC (20\% toluene/Hexane) $R_{f}=0.7 ;{ }^{1} \mathrm{H} \mathrm{NMR}\left(\mathrm{CDCl}_{3}, 400\right.$ $\mathrm{MHz}$ ): $\delta 7.36(\mathrm{~d}, 4 \mathrm{H}, J=8.6 \mathrm{~Hz}), 6.98(\mathrm{~d}, 4 \mathrm{H}, J=8.6 \mathrm{~Hz}), 6.34$ (s, 2H), $1.31(\mathrm{~s}, 6 \mathrm{H}) ;{ }^{13} \mathrm{C} \mathrm{NMR}\left(\mathrm{CDCl}_{3}, 101 \mathrm{MHz}\right.$ )): $\delta 145.4$, $140.4,134.6,130.6,129.2,120.4,50.5,21.9$; GCMS (m/ z(intensities)): 404 (100), 229 (58), 228 (52); Anal. Calcd. For $\mathrm{C}_{19} \mathrm{H}_{16} \mathrm{Br}_{2}$ : C, 56.47; H, 3.99; Found: C, 56.36; H, 4.03.

5,6-bis(4-bromophenyl)-7,7-dimethylnorbornadiene-2,3-dicarboxylic acid (8). Acetylenedicarboxylic acid (23 mg, $0.2 \mathrm{mmol}$ ) was added to a stirring solution of cyclopentadiene $7(50 \mathrm{mg}$, $0.124 \mathrm{mmol})$ dissolved in toluene $(20 \mathrm{~mL})$. After stirring for 8 hours at reflux under an $\mathrm{N}_{2}$ atmosphere, the resulting colourless solution was concentrated in vacuo. The residue was subjected to dry column vacuum chromatography (from heptane to EtOAc-heptane with 10\% increments) yielded light yellow crystals. Yield: $62 \mathrm{mg}, 96 \%$; m.p. $=\sim 160^{\circ} \mathrm{C}$ (decomp.); TLC (EtOAc) $R_{f}=0.1 ;{ }^{1} \mathrm{H}$ NMR (500 MHz, CD $\left.{ }_{3} \mathrm{OD}\right) \delta 7.22(\mathrm{~d}, J=$ 
8.3, 2H), 7.03 (d, $J=8.3,2 \mathrm{H}$ ), $3.76(\mathrm{~s}, 1 \mathrm{H}), 1.17$ (d, $J=12.6$, $2 \mathrm{H}), 1.04(\mathrm{~s}, 2 \mathrm{H}) ;{ }^{13} \mathrm{C} \mathrm{NMR}\left(\mathrm{CD}_{3} \mathrm{OD}, 101 \mathrm{MHz}\right) \delta 146.34$, 135.93, 131.57, 129.10, 121.08, 80.32, 69.68, 21.73, 21.61, 6.42; Anal. Calcd. For $\mathrm{C}_{23} \mathrm{H}_{18} \mathrm{Br}_{2} \mathrm{O}_{4}+1 / 2 \mathrm{H}_{2} \mathrm{O}$ : C, 52.40; H, 3.63; Found: C, 52.48; H, 3.59.

Bis(4-bromphenyl)5,6-bis(4-bromophenyl)-7,7-dimethylnorbornadiene-2,3-dicarboxylate (9). A flame-dried $500 \mathrm{~mL}$ treenecked round-bottom flask equipped with a rubber septum and a reflux condenser was added bis(carboxylic acid) 8 (200 $\mathrm{mg}, 0.386 \mathrm{mmol}$ ) dissolved in dry $\mathrm{CH}_{2} \mathrm{Cl}_{2}$ (40 mL). Oxalyl chloride (1.0 ml, $1.1 \mathrm{mmol}$ ) was added dropwise using a syringe followed by addition of DMF (cat. Amount 2 drops) at $0^{\circ} \mathrm{C}$ under a nitrogen atmosphere. The reaction mixture was allowed to warm to room temperature over a period of 1 hour. The reaction mixture was transferred to a $50 \mathrm{~mL}$ round-bottom flask and evaporated to dryness in vacuo affording the desired crude acid chloride as a light yellow solid. The acid chloride was used immediately in the next step. To the crude acid chloride was added dry $\mathrm{CH}_{2} \mathrm{Cl}_{2}(20$ $\mathrm{mL}$ ), $\mathrm{Et}_{3} \mathrm{~N}(2 \mathrm{~mL}$ ) and 4-bromophenol (260 mg, $1.5 \mathrm{mmol}$ ), followed by addition of 4-dimethylamino-pyridine (DMAP, cat. Amount 2-4 mg). The mixture was stirred at room temperature for 1 hour and concentrated in vacuo. Purification by dry vacuum chromatography (from heptane to EtOAc with $1 \%$ increments) yielded a yellow powder. Yield: $240 \mathrm{mg}$, $74 \%$. m.p. $=296-298^{\circ} \mathrm{C} ; \mathrm{TLC}(20 \%$ EtOAc/Hexane $) R_{f}=0.8$; ${ }^{1} \mathrm{H} \mathrm{NMR}\left(\mathrm{CDCl}_{3}, 400 \mathrm{MHz}\right): \delta 7.40(\mathrm{~d}, 4 \mathrm{H}, J=8.6 \mathrm{~Hz}), 7.33$ (d, $4 \mathrm{H}, J=8.6 \mathrm{~Hz}$ ), 7.12 (d, 4H, $J=8.5 \mathrm{~Hz}$ ), 6.90 (d, 4H, $J=8.5$ $\mathrm{Hz}), 3.89(\mathrm{~s}, 2 \mathrm{H}), 1.37(\mathrm{~s}, 3 \mathrm{H}), 1.35(\mathrm{~s}, 3 \mathrm{H}) ;{ }^{13} \mathrm{C} \mathrm{NMR}\left(\mathrm{CDCl}_{3}\right.$, $101 \mathrm{MHz}$ ): $\delta 162.8,150.8,149.0,145.7,134.9,132.5,131.8$, 128.8, 123.1, 121.7, 119.3, 81.9, 69.2, 29.6, 22.6; Anal. Calcd. For $\mathrm{C}_{35} \mathrm{H}_{24} \mathrm{Br}_{4} \mathrm{O}_{4}$ : C, 50.76; $\mathrm{H}, 2.92$; Found: $\mathrm{C}, 50.52 ; \mathrm{H}, 3.03$; MS (MALDI(TOF)) m/z: calculated for $\mathrm{C}_{35} \mathrm{H}_{24} \mathrm{Br}_{4} \mathrm{O}_{4}+\mathrm{H}_{3} \mathrm{O}^{+}$: 847.2, found: 847.7 .

\section{Acknowledgments}

The Danish Research Council for Independent Research | Natural Sciences [instrument grant \#09-066663], and the Danish National Research Foundation Centre for Molecular Movies, is gratefully acknowledged for financial support.

\section{References}

[1] Christensen M, Haldrup K, Bechgaard K, Feidenhans'l R, Kong Q, Cammarata M, Russo ML, Wulff M, Harrit N, Nielsen MM. Timeresolved X-ray scattering of an electronically excited state in solution. Structure of the $3 \mathrm{~A} 2 \mathrm{u}$ state of tetrakis- $\mu$-pyrophosphitodiplatinate(II). J Am Chem Soc. 2009;131:502-8. doi:10.1021/ ja804485d

[2] Haldrup $K$, Christensen M, Nielsen MM. Analysis of timeresolved X-ray scattering data from solution-state systems. Acta Cryst A. 2010;A66:261-260. doi:10.1107/S01087673090 54233

[3] Haldrup K, Christensen M, Cammarata M, Kong Q, Wulff M, Mariager SO, Bechgaard K, Feidenhans'l R, Harrit N, Nielsen MM. Structural tracking of a bimolecular reaction in solution by time-resolved X-ray scattering. Angewandte Chemie Int. Edition 2009;48:4180-4. doi:10.1364/LS.2009.LSTuC2

[4] Christensen M, Haldrup K, Kjær KS, Cammarata M, Wulff M, Bechgaard K, Harrit NH, Nielsen MM. Structure of a short-lived excited state trinuclear Ag-Pt-Pt complex in aqueous solution by time resolved X-ray scattering. Physical Chemistry Chemical Physics 2010;12:6921-3. doi:10.1039/C002070B

[5] Kim TK, Lee JH, Wulff M, Kong Q, Ihee H. Spatiotemporal kinetics in solution studied by time-resolved X-ray liquidography (solution scattering). ChemPhysChem 2009;10:1958-80. doi:10.1002/cphc.200900154

[6] van der Veen RM, Milne CJ, Nahhas AE, Lima FA, Pham V-T, Best J, Weinstein JA, Borca CN, Abela R, Bressler C, Chergui M. Structural determination of a photochemically active diplatinum molecule by time-resolved EXAFS spectroscopy. Angewandte Chemie Int. Edition 2009;48:2711-4. doi:10.1002/anie.2008 05946

[7] Turro NJ, Cherry WR, Mirbach MF, Mirbach MJ. Energy acquisition, storage, and release. Photochemistry of cyclic azoalkanes as alternate entries to the energy surfaces interconnecting norbornadiene and quadricyclene. J Am Chem Soc. 1977;99:738890. doi:10.1021/ja00464a065

[8] Hirao K, Ando A, Hamada T, Yonemitsu O. Valence isomerisation between coloured acylnorbornadienes and quadricyclanes as a promising model for visible (solar)light energy conversion. J Chem Soc-Chem Commun. 1984;300-2. doi:10.1039/C398400 00300

[9] Cao Y, Zhang BW. New molecular system for solar energy storage. J Photochem Photobiol B-Biol. 1992;15:259-64. doi:10.1016/1011-1344(92)85130-M

[10] Wang XS, Zhang BW, Cao Y. Valence isomerization of norbornadiene in polymer systems for solar energy storage. J Photochem Photobiol A-Chem. 1996;96:193-8. doi:10.1016/1010-6030(95) 04280-6

[11] Dubonosov AD, Bren VA, Chernoivanov VA. Norbornadiene: Quadricyclane as an aboitic system for accumulation of the solar energy. Uspekhi Khimii. 2002;71:1040-50.

[12] Chen JP, Li SY, Zhang L, Liu BN, Han YB, Yang GQ, Li Y. Lightharvesting and photoisomerization in benzophenone and norbornadiene-labeled poly(aryl ether) dendrimers via intramolecular triplet energy transfer. J Am Chem Soc. 2005;127:216571. doi:10.1021/ja044800b

[13] Wu S, Yang G, Zhan Y. Piperazine derivatives used as components in the amine-ketone photocoinitiation system. J Photochem Photobiol A. 1991;61:53-63. doi:10.1016/10106030(91)85080-Z

[14] Yamashita A, Hasebe K, Hirao K. Cycloreversion of electron-rich quadricyclane initiated by metal oxides. Chem Lett. 1992:14812. doi: 10.1246/cl.1992.1481

[15] Cao H, Akimoto Y, Fujiwara Y, Tanimoto Y, Zhang LP, Tung CH. A laser flash photolysis study of the intramolecular energy transfer reaction from benzophenone to norbornadiene covalently bonded by a rigid steroid bridge. Bull Chem Soc Jpn. 1995;68:3411-5. doi:10.1246/bcsj.68.3411

[16] Okada K, Sakai H, Oda M, Kikuchi K. Intramolecular T2-energy transfer from anthryl group studied by stepwise two-color two-photon excitation: a Cis to trans isomerization and a valence isomerization. Chem Lett. 1995:977-8. doi:10.1246/ cl.1995.977

[17] Tung CH, Zhang LP, Li Y, Cao H, Tanimoto Y. Benzophenoneinitiated photoisomerization of the norbornadiene group in a benzophenone-steroid-norbornodiene system via long-distance intramolecular triplet energy transfer. J Phys Chem. 1996;100: 4480-4. doi:10.1021/jp952833v 
[18] Tung CH, Zhang LP, Li Y, Cao H, Tanimoto Y. Intramolecular long-distance electron transfer and triplet energy transfer. Photophysical and photochemical studies on a norbornadienesteroid-benzidine system. J Am Chem Soc. 1997;119:5348-54. doi:10.1021/ja9619925

[19] Petrov VA, Vasil'ev NV. Synthetic chemistry of quadricyclane. Curr Organ Synthesis. 2006;3:215-59. doi:10.2174/15701790 6776819204

[20] Helms AM, Caldwell RA. Triplet species from norbornadiene. Time-resolved photoacoustic calorimetry and ab initio studies of energy, geometry, and spin-orbit coupling. J Am Chem Soc. 1995;117:358-61. doi:10.1021/ja00106a039

[21] Raghavachari K, Haddon RC, Schleyer PV, Schaefer HF. Effects of electron correlation on the energies of 2-norbornyl cation structures. Evaluation of the nonclassical stabilization energy. J Am Chem Soc. 1983;105:5915-7. doi:10.1021/ja00356a034

[22] Turro NJ. Modern Molecular Photochem. Sausalito: University Science Books. 1991. 628 p.

[23] Barwise AJG, Gorman AA, Leyland RL, Smith PG, Rodgers MAJ. A pulse radiolysis study of the quenching of aromatic carbonyl triplets by norbornadienes and quadricyclenes. The mechanism of interconversion. J Am Chem Soc. 1978;100:1814-20. doi:10.1021/ja00474a025

[24] Cuppoletti A, Dinnocenzo JP, Goodman JL, Gould IR. Bondcoupled electron transfer reactions: photoisomerization of norbornadiene to quadricyclane. J Phys Chem A. 1999;103: 11253-6. doi:10.1021/jp992884i

[25] Grutsch PA, Kutal C. Charge-transfer sensitization of the valence photoisomerization of norbornadiene to quadricyclene by an orthometalated transition-metal complex. J Am Chem Soc. 1986;108:3108-10. doi:10.1021/ja00271a053

[26] Hogeveen $\mathrm{H}$, Volger HC. Valence isomerization of quadricyclene to norbornadiene catalyzed by transition metal complexes. J Am Chem Soc. 1967;89:2486. doi:10.1021/ja00986a045

[27] Rogers DW, Choi LS, Girellini RS, Holmes TJ, Allinger NL. Heats of hydrogenation and formation of quadricyclene, norbornadiene, norbornene, and nortricyclene. J Phys Chem. 1980;84: 1810-4. doi:10.1021/j100451a014

[28] Roos BO, Merchan M, McDiarmid R, Xing X. Theoretical and experimental determination of the electronic spectrum of norbornadiene. J Am Chem Soc. 1994;116:5927-36. doi:10.1021/ ja00092a049

[29] Wilson HD, Rinker RG. Kinetics of quadricyclene-norbornadiene isomerization reaction for use in modeling supported liquid- phase catalysis. J Catal. 1976;42:268-74. doi:10.1016/00219517(76)90261-X

[30] Gilman H, Young RV. Relative reactivities of organometallic compounds. XV. Organoalkali compounds. J Organic Chem. 1936;1:315-31. doi:10.1021/jo01233a001

[31] Finley KT. Acyloin condensationasa cyclization. Chem Rev. 1964;64:573-589. doi:10.1021/cr60231a004

[32] Ruhlmann K. Synth-Internat J Methods Synth Organic Chem. 1971:236.

[33] Maruyama K, Tamiaki H. Catalytic isomerization of watersoluble quadricyclane to norbornadiene derivatives induced by cobalt-porphyrin complexes. J Organic Chem. 1986;51:602-6. doi:10.1021/jo00355a006

[34] Dubonosov AD, Bren VA, Minkin VI. In: Horshpool W, Lenci F, editor. Florida: CRC Press; 2000.

\section{Competing Interests}

We declare that we have no conflicts of interest with the industry.

\section{Publishing Notes}

(C) 2014 P. Hammershøj et al. This work has been published open access under Creative Commons Attribution License CC BY 4.0, which permits unrestricted use, distribution, and reproduction in any medium, provided the original work is properly cited. Conditions, terms of use and publishing policy can be found at www.scienceopen.com.

Please note that this article may not have been peer reviewed yet and is under continuous post-publication peer review. For the current reviewing status please click here or scan the QR code on the right.

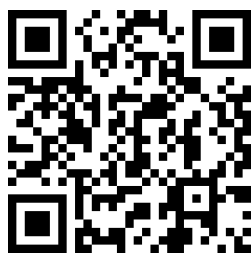

\section{scienceOPEN.com}

research+publishing network 